\title{
Microwave absorption capacity of rice flour. Impact of the radiation on rice flour microstructure, thermal and viscometric properties
}

\author{
Marina Villanueva a, Joanna Harasyma, b, José María Muñoz ${ }^{\mathrm{c}}$, Felicidad Ronda ${ }^{\mathrm{a} *}$ \\ ${ }^{a}$ Department of Agriculture and Forestry Engineering, Food Technology, College of \\ Agricultural and Forestry Engineering, University of Valladolid, Spain \\ ${ }^{\mathrm{b}}$ Bio-Ref Lab, Department of Biotechnology and Foods Analysis, Institute of Chemistry and \\ Food Technology, Faculty of Engineering and Economics, Wrocław University of Economics, \\ Wrocław, Poland. \\ ${ }^{\mathrm{c}}$ Department of Electricity and Electronics, University of Valladolid, Valladolid, Spain \\ *Corresponding author: Av. Madrid, s/n, 34004, Palencia, Spain, fronda@iaf.uva.es
}

\begin{abstract}
The microwave radiation thermal treatment of rice flour was studied and its impact on physical and structural characteristic in relation to the initial moisture content (IMC) (20\% and 30\%) was evaluated. To explain the fundamentals of observed changes the microwave radiation absorption capacity of flour as well as temperature and moisture change during the treatment were evaluated. The flour particle morphological structure as well as crystallinity/amorphous region ratio changed after the treatment. The flour thermal properties also altered revealing IMC significant impact on the gelatinization temperature, that rised up to $3^{\circ} \mathrm{C}$, and the amylopectin retrogradation extent that increased up to a $7 \%$ in the most intense microwave-treated flours with respect to the native flour. Lower peak, setback and breakdown viscosities -that decreased with respect to the native flour up to $42 \%, 34 \%$ and $86 \%$ respectively-and higher pasting temperatures -that increased up to $10{ }^{\circ} \mathrm{C}$ - were also observed. An exceptional microwave irradiation efficiency resulting in rice flour physical changes in significantly shorter times, 4-8 min, than conventional heat-moisture treatment processes was concluded.
\end{abstract}

Keywords: Microstructure; Microwave treatment; microwave absorptivity; pasting properties; rice flour; thermal properties

\section{Introduction}

Rice flour, due to its low allergenicity is one of the most utilized raw materials in gluten-free production. However, the functional properties of native rice flour are insufficient for the creation of highly developed and stable dough structure. For improvement of rice flour functionality several different modification procedures were employed including hydrocolloids and fiber addition (Perez-Quirce et al, 2017; Ronda et al., 2015), enzyme application (Kim, 2016), protein enrichment (Villanueva et al., 2015; Phongtai et al., 2017), milling and particle size classification (Yano et al., 2017), high pressure processing (Cappa et al., 2016) and hydrothermal treatment in the excess of water (Bourekoua et al., 2016). 
Microwave (MW) radiation can deliver energy with high efficiency depending mainly on dielectric properties of a treated sample. Therefore microwave treatment (MWT) provides a faster method than conventional heating to perform common hydrothermal treatment (HMT). MW are electromagnetic waves with frequencies between 1 and $300 \mathrm{GHz}$ that polar and ionizable molecules (water and mineral salts, mainly) may absorb efficiently. The energy absorption takes place at a molecular level, producing a rapid increase in the temperature of all the sample volume, which significantly differentiates MW and convectional thermal heating. MWT impact studies on the physicochemical, structural and functional properties of cereals and legumes starches were carried out, but the effect on flours has been so far little studied.

Anderson and Guruya (2006) evaluated the effect of MWT of waxy and non-waxy rice starches at $20 \%$ water content revealing significant changes in viscosity properties after microwave irradiation exposure. Ashraf et al. (2012) studied the effect of MWT on the functional properties of wheat and red bean flour and showed that MWT improved the water holding capacity, oil absorption, emulsifying and foaming ability and proteins solubility index. However, there is a lack of processing data e.g. the mixing characterizing and microwave radiation distribution as well as moisture evaluation during the treatment which is crucial for the proper evaluation of the microwaves' impact.

To develop effective microwave treatments, the dielectric properties of raw materials are critical as they measure the ability to store and absorb electromagnetic energy. The dielectric properties of interest are the dielectric constant $\varepsilon^{\prime}$ and loss factor $\varepsilon^{\prime \prime}$, the real part and imaginary part, respectively, of the relative complex permittivity (Guo et al., 2010):

$$
\varepsilon=\varepsilon^{\prime}+j \varepsilon^{\prime \prime}(j=\sqrt{-1})
$$

The $\varepsilon^{\prime}$ mainly reflects the ability of a material to store electromagnetic energy and $\varepsilon^{\prime \prime}$ represents its ability to absorb it. Therefore the microwave attenuation of a sample is related to dielectric losses $\left(\varepsilon^{\prime \prime}\right)$ of studied flour while phase change is related to dielectric permittivity ( $\left.\varepsilon^{\prime}\right)$ of flour. The measurement of microwave dielectric properties of raw materials as a function of its water contents can be a useful method to estimate the effect of microwave radiation on other properties as well as to discriminate bound water from the total water content thanks to its different contribution to dielectric permittivity and loss. As the moisture is the functional variable of MWT, it is crucial to determine its specific contribution to flour heat absorption and physical modification during the microwave irradiation.

The microwave radiation physical modification of rice flour and its water content effect have not been studied up until now in spite of the fact that rice flour is a raw material more extensively used in gluten-free products formulation. The main objectives of this study were to analyze the microwave radiation absorption capacity of rice flour as a function of its water content and the microwave assisted thermal treatment impact on the physical characteristic, thermal and pasting properties of rice flour. Moreover the procedure to obtain a uniform distribution of MW radiation within the sample to avoid flour burning/darkening was designed, and water content of the flour was controlled during the MWT to evaluate the relative importance of HMT and dry-heat-treatment (DHT).

\section{Materials and Methods}

\subsection{Rice flour}


Indica rice variety commercially available flour Herba NAT 300 (Herba Ricemills S.L.U., Tarragona, Spain) was used for all experiments. The initial water content was $13 \%$, ash $<0.9 \%$, protein $>6.5 \%$, fat $<1 \%$ and gluten $<10 \mathrm{ppm}$. The flour granulometry was as follows: $1 \%$ $<250 \mu \mathrm{m}, 250 \mu \mathrm{m}>10-20 \%>210 \mu \mathrm{m}, 210 \mu \mathrm{m}>35-45 \%>150 \mu \mathrm{m}, 150 \mu \mathrm{m}>20-35 \%>100$ $\mu \mathrm{m}$ and $100 \mu \mathrm{m}<10-20 \%$ (data provided by manufacturer).

\subsection{Flour preparation}

Initial rice flour water content was measured with Official Method AACC 44-19 (AACC, 2000) and the amount of water added for certain water content levels achievement was calculated. Flour water content levels were set at $2.5 \%, 5 \%, 10 \%, 13 \%, 15 \%, 25 \%, 30 \%$ and $39 \% \pm 0.5 \%$. The water content of $2.5 \%$ was obtained by rice flour lyophilization in FreeZone 1, Labconco (Kansas City, USA) lyophilizer. The calculated amount of water was sprayed onto the flour mixed in Teddy Bear mixer Mono Equipment (Swansea, UK) within 10 minutes. Water contents of 5 and $10 \%$ were obtained by mixing calculated amounts of $13 \%$ rice flour with lyophilized one. The prepared samples were stored for 24 hours at $4 \pm 2^{\circ} \mathrm{C}$ for equilibration.

The water activity of flours was measured with Testo 650 Humidity Meter provided with a high precision relative humidity probe TESTO (Lenzkirch, Germany). Determination was made in duplicate at $25^{\circ} \mathrm{C}$.

\subsection{Microwave absorption capacity of rice flours}

Rice flour samples of different water contents were weighted and carefully homogenously distributed in Petri dishes. Absorption was measured with Keysight (Agilent) E5071C network analyzer with both port connected via coaxial lines and attenuators to two coaxial waveguide (SMA to WR340) transitions. The two 40dB attenuators were placed between the coaxial lines and the waveguide transitions to minimize the impedance mismatch between a coaxial line joining the analyzer (50 ohms) and transition (the impedance depends on the measured sample) by reduction of stationary waves in those lines with the goal of improving the determination. The waveguides were aligned and faced each other at a constant distance and the $11 \mathrm{~mm}$ deep Petri dishes, with homogenously dispersed flour, were placed between them. The analyzer was configured to work between 2 and $3 \mathrm{GHz}$ and to measure the scattering coefficient $\mathrm{S}_{12}$. It was calibrated with an empty Petri dish for $0 \mathrm{~dB}$ and $0^{\circ}$ of phase angle. Absorption was measured at $2.5 \mathrm{GHz}$ because is the same frequency used by home microwave ovens and the only frequency that can be used without special permits. All samples were measured in duplicate.

In our system -moistened flour- water was responsible for microwave absorption while flour played the role of diluent. The application of the Lambert-Beer law required the normalization of the measurement to sample weight since the optical path could not be completely filled with the sample but also included air entrapped between the flour particles. The microwave absorption was expressed in terms of attenuation, calculated from the ratio of the power measured with the sample and the one obtained with an empty Petri dish (in $\mathrm{dB}$ ) and in terms of phase change, calculated as phase shift of the received signal when placing the sample (in degrees), by using the following equations:

$$
\begin{aligned}
& \alpha=20 \cdot \log \frac{S_{12}(\text { filled })}{S_{12}(\text { empty })} \\
& \Theta=\arg \frac{S_{12}(\text { filled })}{S_{12}(\text { empty })}
\end{aligned}
$$


Where $\alpha$ is attenuation, $\Theta$ is the phase shift, $S_{12}$ is the scattering coefficient when the sample container is filled with a sample $\left(\mathrm{S}_{12}\right.$ (filled)) or empty $\left(\mathrm{S}_{12}(\mathrm{empty})\right)$.

In terms of power, the attenuation can be obtained from the formula:

$$
\alpha=10 \cdot \log \frac{P(\text { filled })}{P(\text { empty })}
$$

Where $P($ filled $)$ is the power detected for the sample filled Petri dish and $P($ empty $)$ is the power detected for the empty Petri dish. The actual value of the complex permittivity is difficult to measure without waveguide sample holders, which require, at these frequencies, an inordinate amount of sample material.

\subsection{Microwave treatment}

The microwave treatment was provided with customized microwave oven (900 W) R342INW (Sharp, Sakai, Japan). Preliminary studies were undertaken for setting the microwave treatment conditions. Finally, $100 \mathrm{~g}$ of flour with two levels of initial water content (20\% and 30\%), were placed in a polyethylene container closed with a plastic film with a few (4-5) needle made small holes and continuously stirred by an external device at a speed of 60-70 rpm. The flour was exposed to microwave radiation for $2,4,6,8,12$ and $16 \mathrm{~min}$ in cycles of $20 \mathrm{~s}$ of exposure and 40 s of rest.

The flour temperature evolution during the MWT was measured with Testoterm thermometer strips of different scales, and $0.5^{\circ} \mathrm{C}$ accuracy, from TESTO (Barcelona, Spain). Two strips of different scale were introduced with each sample into the polyethylene container and were continuously stirred and in contact with the sample during the established treatment time. Each measurement was made in duplicate.

\subsection{Scanning electron microscopy (SEM)}

A microscope model Quanta 200-F (FEI, Oregon, USA) was used to study the morphological changes in the flours. This microscope was equipped with an X-ray detector which allowed the analysis of samples of low conductivity without prior metallization. The samples were directly mounted on stubs and observed with an accelerating voltage of $1.5 \mathrm{keV}$.

\subsection{X-Ray Diffraction}

The diffraction assessment was proceeded using a Bruker-D8-Discover-A25 diffractometer (Bruker AXS, Rheinfelden, Germany) equipped with a copper tube operating at $40 \mathrm{kV}$ and 40 $\mathrm{mA}$, with $\mathrm{CuK} \alpha$ radiation of 0.154-nm wavelength. Diffractograms of samples were obtained with scanning from $5^{\circ}$ to $40^{\circ}(2 \theta)$ at a rate of $1.2^{\circ} / \mathrm{min}$, a step size of $0.02^{\circ}$, a divergence slit width variable of $5 \mathrm{~mm}$ and a scatter slit width of $2.92^{\circ}$ and a nickel filter 0.02 to exclude the $\mathrm{K} \beta$ radiation.

The crystallinity of samples was determined from diffractograms based on the relation between the global peaks area and the reduced peaks area assigned to the crystalline part of the sample, and expressed as a percentage. The "search-match" software DifracEVA with PDF2-2004 and COD database was used for this purpose.

\subsection{Differential Scanning Calorimetry}


Gelatinization and retrogradation transitions were assessed by DSC (DSC-822e, Mettler Toledo, SAE). Flour samples, $\sim 6 \mathrm{mg}$, were weighed into aluminum pans $(40 \mu \mathrm{l})$ and distilled water was added to achieve the ratio 30:70 (flour:water). The samples were scanned from 0 to $115^{\circ} \mathrm{C}$ at $5^{\circ} \mathrm{C} /$ min using an empty pan as reference. The retrogradation of starch was evaluated in the samples previously gelatinized in the DSC pans after 7 days of storage at $(4 \pm 2){ }^{\circ} \mathrm{C}$ following the same protocol. The enthalpy $(\Delta \mathrm{H})$ values, $\mathrm{J} / \mathrm{g}$ of solids, the onset and peak temperatures (To and $\mathrm{Tp}$ ), and the temperature range $\left(\mathrm{R}_{\mathrm{gel}}=2 \cdot(\mathrm{Tp}-\mathrm{To})\right)$ for the gelatinization peak, were established. Samples were run in duplicate.

\subsection{Pasting Properties of Flours}

Pasting properties were studied by using the Rapid-Visco-Analyzer (RVA-4, Newport Scientific Pvt. Ltd., Australia) using ICC Standard method 162. Untreated flour was also measured as control. The pasting temperature (PT), peak time (VT), peak viscosity (PV), trough viscosity (TV), breakdown (BD), final viscosity (FV), and setback (SB) were calculated from the pasting curve using Thermocline v.2.2 software. The determination was carried out in triplicate.

\subsection{Statistical analysis}

The Statgraphics Centurion v.16 (Bitstream, Cambridge, MN, USA) software was used for MANOVA and ANOVA analyses. The Fisher's least significant difference (LSD) test was adopted to evaluate significant differences $(\mathrm{p}<0.05)$ among samples. Homogeneity of variance was checked for each studied variable.

\section{Results and Discussion}

\subsection{Microwave absorption capacity of flour}

The microwave radiation absorption capacity of rice flour, measured in terms of attenuation, and the phase shift of radiation when it passed through the samples as function of their water content are shown in Fig. 1A. The MW attenuation data are also represented, simultaneously with the water content of rice flour, versus flour water activity, $a_{w}$, in Fig.1B. The MW attenuation and phase shift increased with water content according to the equations:

$$
\begin{gathered}
\operatorname{Attenuation}(\mathrm{dB} / \mathrm{g})=1.10( \pm 0.16) \cdot 10^{-5} \cdot \mathrm{W}^{2}+9.00( \pm 1.1) \cdot 10^{-4} \cdot \mathrm{W}-1.2( \pm 1.4) \cdot 10^{-3} \\
R^{2}=99.8
\end{gathered}
$$

Phase-shift $(\Theta)=0.0064( \pm 0.0017) \cdot W^{2}+0.37( \pm 0.12) \cdot W+20.6( \pm 1.5)$

$$
R^{2}=99.0
$$

Where $\mathrm{W}$ is the water content expressed in $\mathrm{g} / 100 \mathrm{~g}$ solids. The standard error of each regression coefficient is given in parentheses. These results reveal that the greater the total amount of water contained in the flour the smaller is the signal reaching the receiver. This is due, on the one hand, to the fact that there is a greater absorption of radiation by the sample and on the other hand, that the proportion of incident radiation that is reflected by the sample is greater, since its dielectric permittivity is also greater. The combination of these two effects justifies the positive deviation from Beer's law that shows the absorption curve approaching a quadratic rather than a linear behavior. This fact cannot be confirmed, since it is possible that the increase of the attenuation is due to an increase in the reflected radiation and not in the absorbed one. The 
independent term of Eq.5 is not significantly different from zero which means attenuation is zero when the flour is completely dry. In consequence, it can be concluded that flour dry matter is unable to absorb the microwave radiation even though flour could experience a faster heating under MW-radiation when it loses water (Lewandowicz et al., 1997). This effect must be due to the dramatic reduction in flour specific heat with the reduction of its water content.
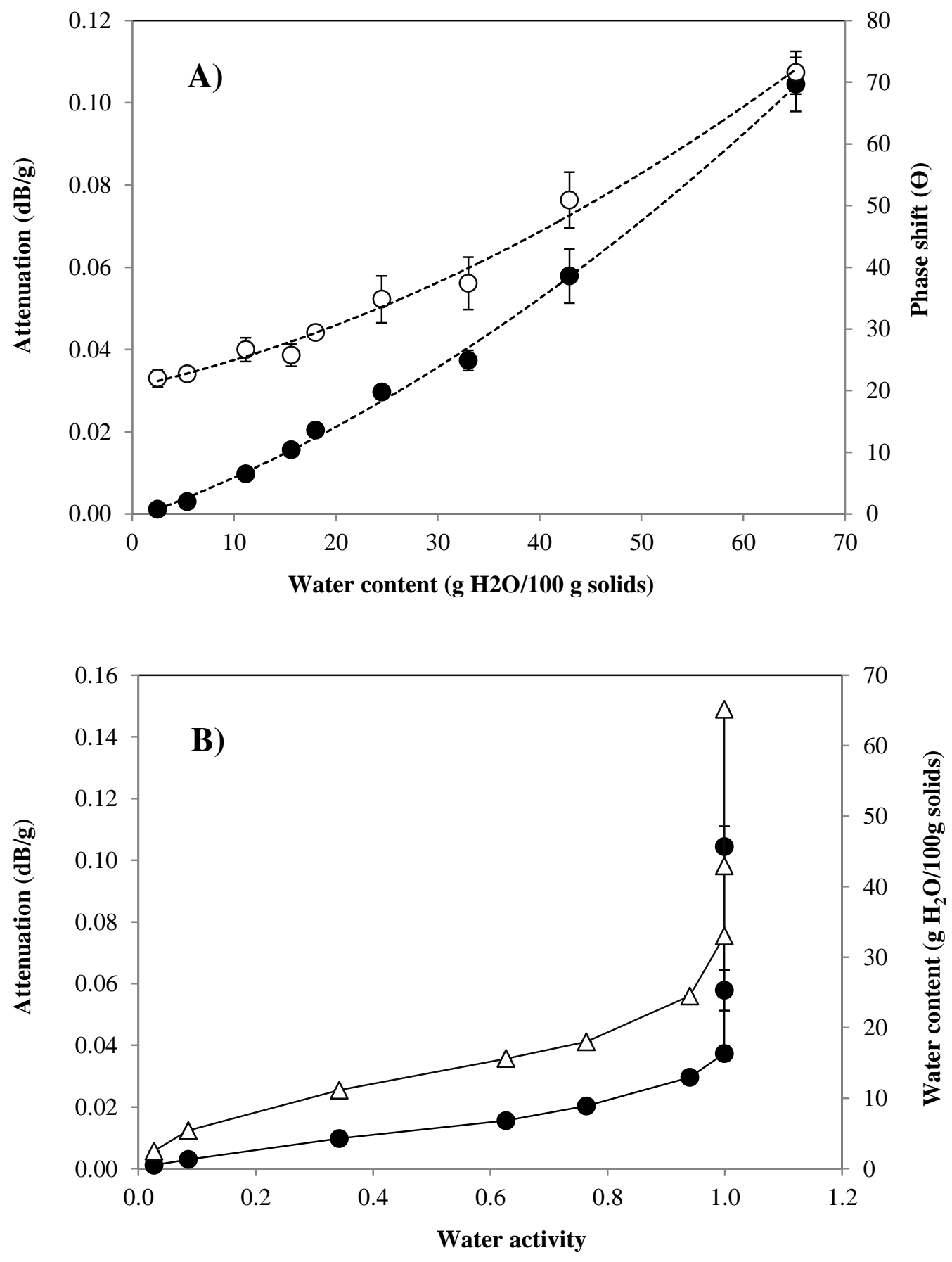

Figure 1. Attenuation of microwave radiation by rice flour in function of its water content and water activity. A) Attenuation (O) and phase shift $(\bigcirc)$ of rice flour in function of its water content. B) Attenuation $(\mathbf{O})$ and water content $(\Delta)$ versus water activity. 
Figure 1B shows a total parallelism in the evolution of water content and attenuation versus $\mathrm{a}_{\mathrm{w}}$. This indicates that the microwave absorption capacity of flour does not depend on water activity since the attenuation increased drastically even when $a_{w}$ hardly varied around $a_{w}=1$, but depends on the total water content of the flour. These results also indicate that the attenuation and the phase shift measurements may be a fast, simple, and accurate method for determining in line the moisture content of rice flour as they allow a remote and non-destructive measurement of the flour, as concluded by Ince and Turner (1965), in biscuits investigations and Okabe et al. (1973), in rice and wheat grains study.

\subsection{Temperature evolution in flour during the microwave treatment}

The evolution of the temperature and the water content of the flours during MWT are shown in Fig.2. As can be seen, it decreased in $8 \mathrm{~min}$ to $8 \%$ and $10 \%$ for the flours moistened to $20 \%$ and $30 \%$ respectively. These results suggest that MWT in a non-hermetic container, is in fact, the combination of two processes: HMT, in the first stage, and DHT in the last one. As can be seen in Fig. 2 during the first 80 s of treatment the energy absorbed by the samples was mainly involved in changing its temperature, while at 80 s both flours attained a small plateau of constant temperature, where the heat absorbed by the sample was involved in boiling its small amount of free water. After that, the temperature increased again to attain a new plateau, after 4-5min of MW radiation, where the temperature was constant until the end of the treatment. The maximum temperature achieved by the samples was $150 \pm 10^{\circ} \mathrm{C}$. In the first $20 \mathrm{~s}$ of treatment, the flours with $20 \%$ and $30 \%$ water content reached $46^{\circ} \mathrm{C}$ and $60^{\circ} \mathrm{C}$, respectively. The higher microwave absorption capacity could explain the higher temperature as was seen in our previous work (Pérez-Quirce et al., 2016). However, between 20s and 80s both samples showed similar temperature profile probably due to the fact that the higher energy absorption was compensated with the higher specific heat that makes this flour need more absorbed heat to get a similar change in temperature.

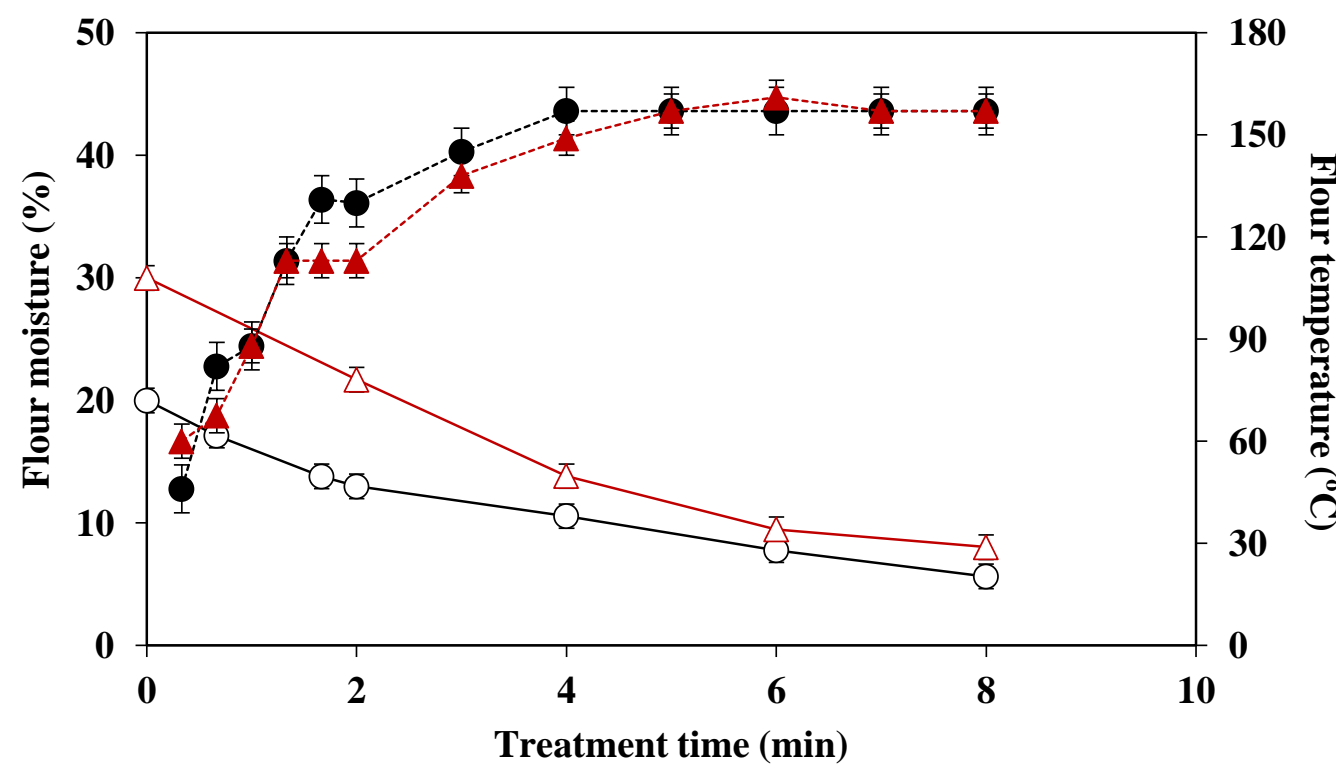

Figure 2. Evolution of moisture $(O, \Delta)$ and temperature $(\mathbf{O}, \mathbf{\Delta})$ of the flour as a function of microwave treatment of moistened rice flours at $20 \%(\boldsymbol{\bullet}, \bigcirc)$ and $30 \%(\boldsymbol{\Delta}, \Delta)$ initial hydration levels. 
The boiling temperature of the flour with $20 \%$ initial moisture was higher than that of the flour with $30 \%$ because its water activity (Fig.1B), and in consequence its water vapor pressure, was lower in the former, which means a higher temperature needed to attain the external atmospheric pressure and to reach the boiling conditions. After $4 \mathrm{~min}$ of MWT the water content of the flour was of 5-10\% (Fig.2), near the value corresponding to the rice flour monolayer water content (Abebe \& Ronda 2015) which corresponds to water tightly bound. The final long plateau of constant temperature probably corresponded to a period in which the heat absorbed by the sample (not too much as the water amount was really low) was equal to the heat lost by it towards the surrounding that increased with the temperature of the sample. In our previous work, where the sample was treated inside a hermetic container, a single and long temperature plateau was obtained below $100^{\circ} \mathrm{C}$, with water acting as 'protector' of the flour constituents, which was used to explain the low impact of the MWT in such conditions on flour functional properties (Pérez-Quirce et al., 2016), differently to what we have observed in this case.

\subsection{Morphology of samples}

From SEM images (Fig. 3) the important impact ofMWT on flour particles macrostructure of samples moistened at $20 \%$ and $30 \%$ can be concluded. Rice starch differs by its shape from other cereals and the granules are polygonal and are packed very tightly in the rice grain cells being entwined with globular protein bodies and lipids (Nawaz et al., 2016). The starch granules form polygonal macrostructures often visible in SEM micrographs of rice kernel (Siruguri et al., 2009). After milling of rice these macrostructures appear more or less intact in the flour (see Fig. 3-A1). With the increase of water content in flours treated with MW, the characteristic of particle size distribution was narrowed resulting in more homogenous one (see Fig. 3-B1-C1) which was probably caused by gluing the small particles together. The subsequent magnification revealed that primarily rough and frayed particle shapes in native flour become more rounded and ovoid (Fig. 3-A2-B2-C2) in treated samples which was also confirmed previously by Takahashi et al. (2005) for short grain rice autoclaved at $20 \%$ of moisture content. The particles' surface (Fig.3-A3-B3-C3) appears to be smoother and aligned similar as reported by other researchers for short rice grain flour (Majzoobi et al., 2016) and foxtail millet flour (Amadou et al., 2014) when were submitted to convectional hydrothermal treatments. At highest magnification starch granules clusters were visible covered by protein bodies spread and adhered over the surface (Fig. 3-A4-B4-C4). The resulting macrostructures (Fig. 3-A4-B4-C4) revealed that starch granules in clusters seem to be glued with neighboring ones and the slots between them visible at native flour were shallow and filled in MW-treated ones. Such sealing could be the result of amylose exudation during the thermal treatment of native flour as previously reported (Carrera et al., 2015). Such behavior was not reported for isolated starch treatment and presents the additional difference between HMT treatment of starch and flour.

\subsection{X-ray diffraction and crystallinity of samples}

The X-ray diffraction patterns of rice flour treated for 4 and 8 min are presented in Fig.4. All the rice flour samples presented an A-type diffraction pattern with crystalline peaks at $10^{\circ}, 15^{\circ}, 17^{\circ}$, $18^{\circ}, 23^{\circ}$ and $26^{\circ}$, maintained after the treatment. The reflection at $20^{\circ}$, which is usually connected with V-crystallinity, was also observed in all rice flour although the peak increased in the MW-treated samples about $14 \%$ in ones with the highest water content and the longest treatment (30\%-8min). 
A) CONTROL
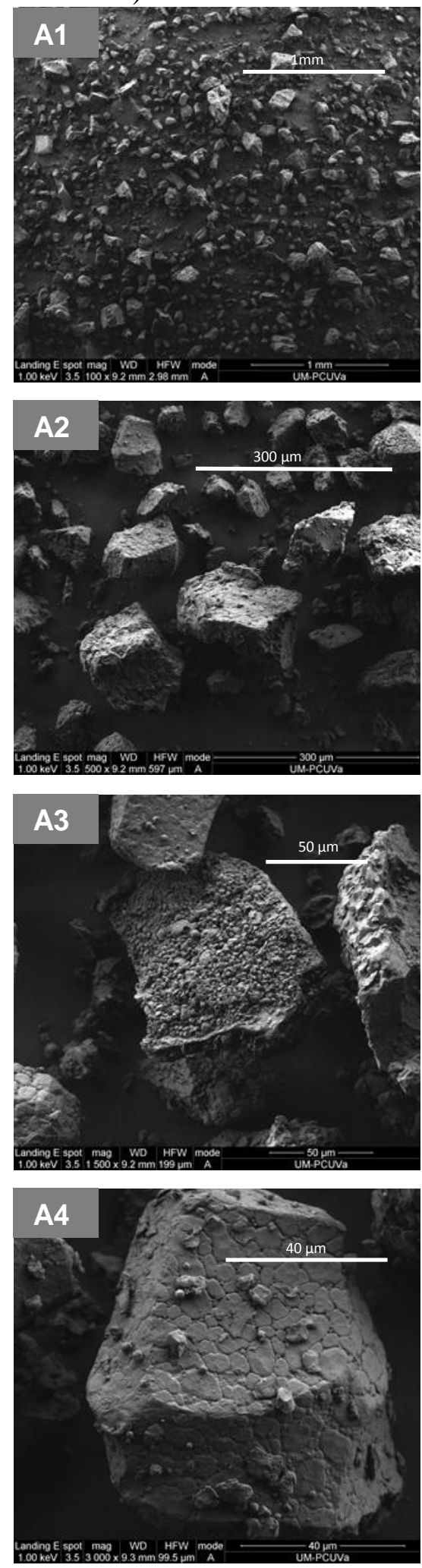

B) $20 \%$
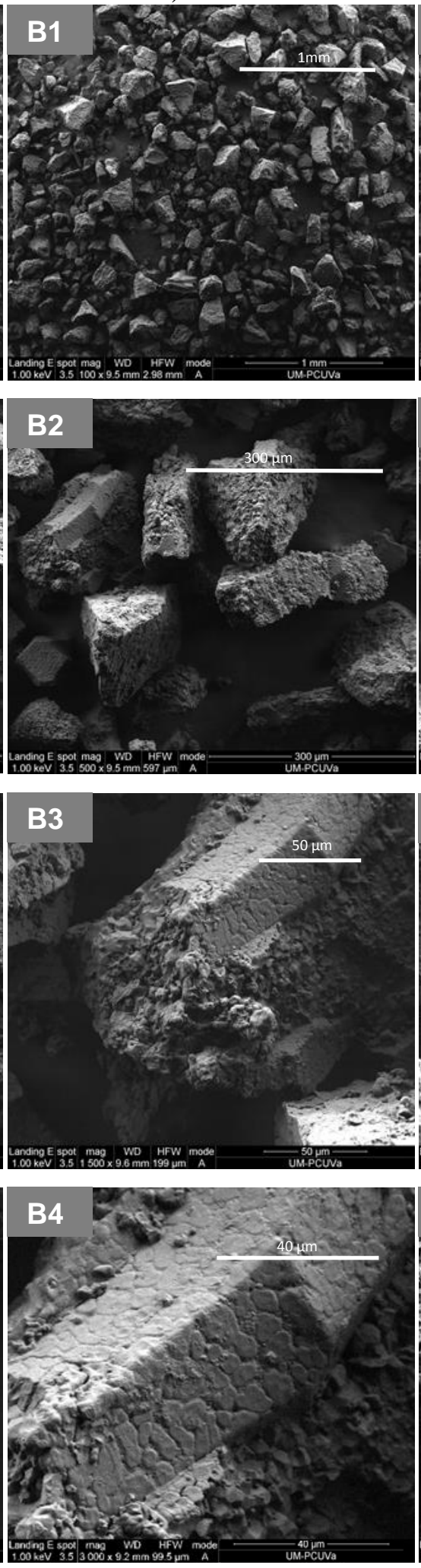

C) $30 \%$
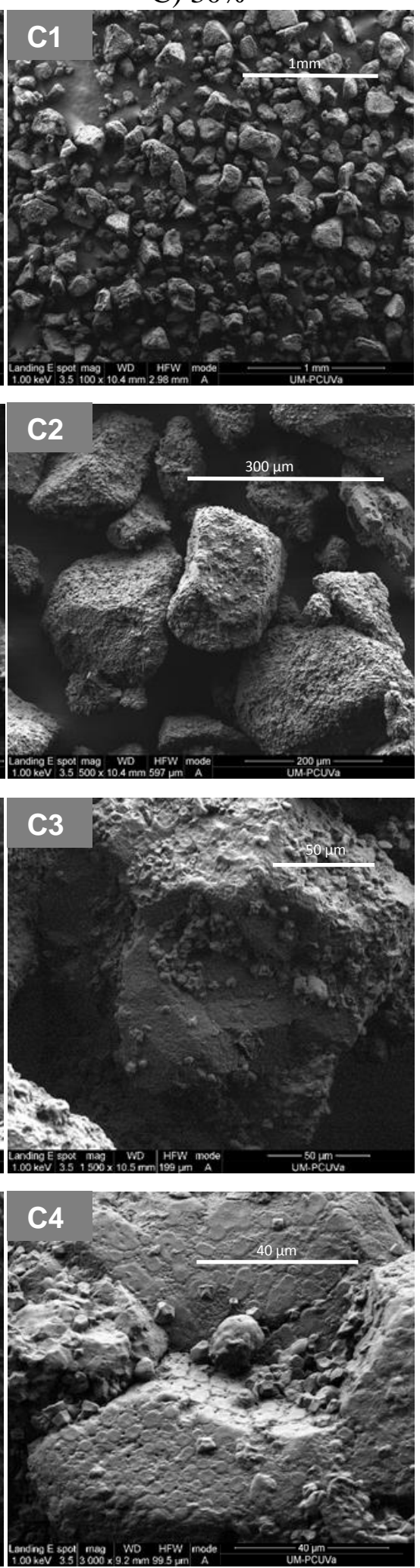

Figure 3. SEM pictures of rice flour particles at different magnifications (100x, 500x, 1500x and 3000x). A: untreated flour (control), B: flour with an initial water content of $20 \%$ treated by microwave radiation for $8 \mathrm{~min}, \mathrm{C}$ : flour with an initial water content of $30 \%$ treated by microwave radiation for $8 \mathrm{~min}$. 
This suggests an increase in the amylose-lipid complex, although it did not result in an increase in the enthalpy of the complex dissociation obtained by DSC (see section 3.5). The duplex at $17^{\circ}$ and $18^{\circ}$ also changed the intensity of reflection revealing changes in crystallinity. The most intensive reflection was observed for the flour treated $8 \mathrm{~min}$ at $20 \%$ moisture resulting in a crystallinity of $67.4 \%$ vs $61.5 \%$ for control, untreated flour. Usually, for HMT the relative crystallinity of the flours was lower than those from control (Zavareze and Dias, 2011; Silva et al, 2017). The conditions of typical HMT processes (high moisture, high temperature, long time) afford increased mobility to the starch chains and helical structures, resulting in structural changes in both the crystalline and amorphous regions of the starch granules. This mobility allows the disruption of the least stable structures of crystalline regions, altering organization of highly ordered helical structures and/or crystallites within granules (BeMiller \& Huber, 2015). However, MWT, due to much faster and uniform heat distribution as well as local superheating points and the loss of water during the process, can lead to other structure rearrangements reflecting in higher final crystallinity. Similar results were obtained by Qiu et al. (2015) during dry heat treatment of rice flour which resulted in higher crystallinity of both rice flour and starch. These authors suggested that dry heat treatment may contribute to the formation of new crystallites or recrystallization and perfection of the small crystalline regions of the starch granule.

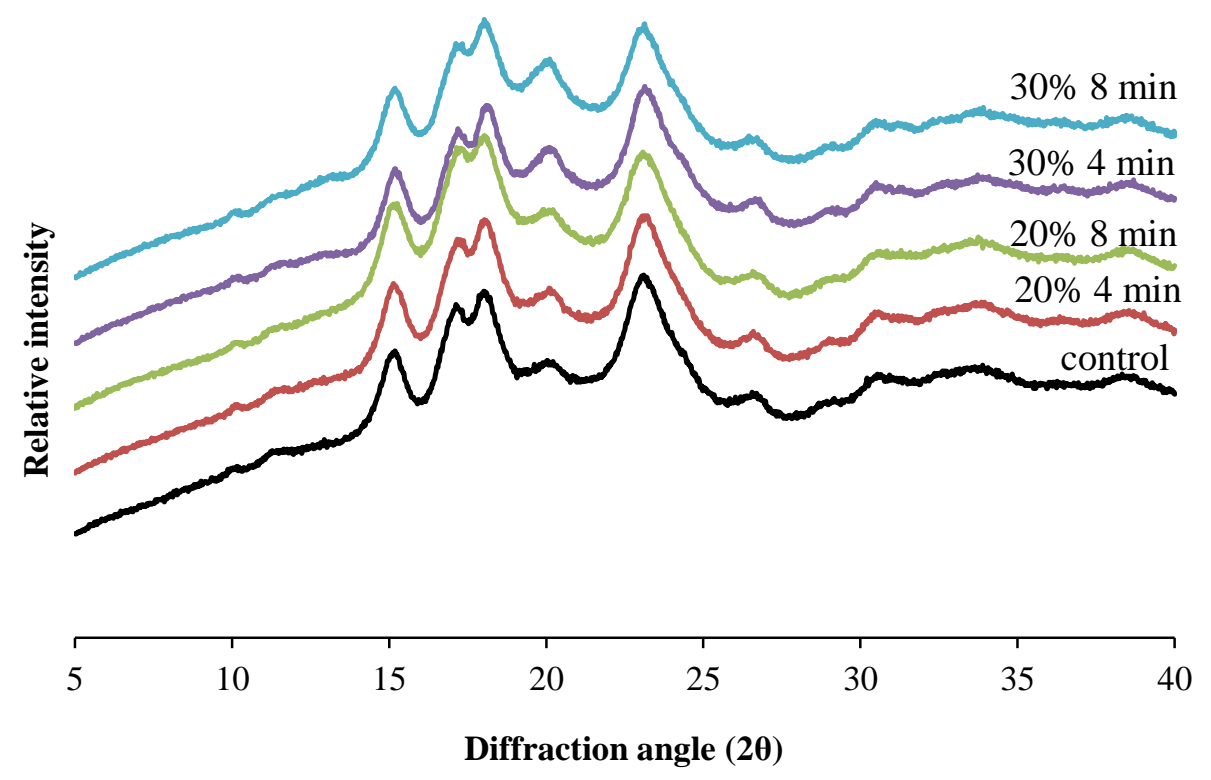

Figure 4: X-ray diffraction patterns of untreated rice flour (control) and microwaved (different treatment times) rice flours at initial moisture contents of $20 \%$ and $30 \%$.

\subsection{Effect of microwave treatment on thermal properties of rice flour}

The thermal properties of MW-treated rice flour are presented in Table 1. All the samples exhibited two endotherms. The first one, which appeared at $74-77^{\circ} \mathrm{C}$, corresponded to the melting of the amylopectin crystallites in the starch granules and the second one, at $96-97^{\circ} \mathrm{C}$, was due to the dissociation of the amylose-lipid complex (Eliasson, 1994). The effect of microwave treatment was significantly dependent on the initial water content of the flour. However, the treatment time, in the range studied, had no effect on any thermal property. The 
Table 1. Thermal properties of aqueous dispersions ( $70 \%$ solids) of rice flour treated by microwaves

\begin{tabular}{|c|c|c|c|c|c|c|c|c|c|c|c|}
\hline $\begin{array}{c}\text { Initial } \\
\text { Moisture } \\
\text { Content } \\
(\% \text { fb }) \\
\end{array}$ & $\begin{array}{l}\text { Microwave } \\
\text { treatment } \\
\text { time } \\
(\mathrm{min}) \\
\end{array}$ & $\begin{array}{l}\Delta \mathbf{H}_{\text {gel- }} \\
\text { First } \\
(\mathbf{J} / \mathbf{g ~ d b})\end{array}$ & $\begin{array}{l}\mathrm{T}_{\text {o-gel- }} \\
\text { First } \\
\left({ }^{\circ} \mathrm{C}\right)\end{array}$ & $\begin{array}{l}\mathbf{T}_{\text {p-gel- }} \\
\text { First } \\
\left({ }^{\mathbf{0}} \mathrm{C}\right)\end{array}$ & $\begin{array}{l}\mathbf{R}_{\text {gel- }} \\
\text { First } \\
\left({ }^{\circ} \mathrm{C}\right)\end{array}$ & $\begin{array}{l}\Delta \mathbf{H}_{\text {am-lip- }} \\
\text { First } \\
(\mathbf{J} / \mathbf{g ~ d b})\end{array}$ & $\begin{array}{l}\mathbf{T}_{\text {p-am-lip- }} \\
\text { First } \\
\left({ }^{\circ} \mathrm{C}\right)\end{array}$ & $\begin{array}{l}\Delta \mathbf{H}_{\text {am-lip- }} \\
\text { Second } \\
(\mathbf{J} / \mathbf{g ~ d b})\end{array}$ & $\begin{array}{l}T_{\text {p-am-lip- }} \\
\text { Second } \\
\left({ }^{\circ} \mathrm{C}\right)\end{array}$ & $\begin{array}{l}\Delta \mathbf{H}_{\text {ret- }} \\
\text { Second } \\
(\mathrm{J} / \mathrm{g} \\
\mathrm{db}) \\
\end{array}$ & $\begin{array}{l}T_{\text {p-ret- }} \\
\text { Second } \\
\left({ }^{\circ} \mathrm{C}\right)\end{array}$ \\
\hline Control & 0 & $10.3^{\mathrm{d}}$ & $68.1^{\mathrm{a}}$ & $74.0^{\mathrm{a}}$ & $11.8^{\mathrm{b}}$ & $1.1^{\mathrm{b}}$ & $96.0^{\mathrm{a}}$ & $2.8^{\mathrm{b}}$ & $96.7^{b}$ & $4.5^{\mathrm{a}}$ & $55^{\mathrm{a}}$ \\
\hline 20 & 4 & $9.6^{\mathrm{bc}}$ & $68.5^{\mathrm{a}}$ & $74.4^{\mathrm{b}}$ & $11.8^{\mathrm{b}}$ & $1.0^{\mathrm{b}}$ & $96.3^{\mathrm{ab}}$ & $2.4^{\mathrm{ab}}$ & $97.3^{\mathrm{b}}$ & $4.3^{\mathrm{a}}$ & $54^{\mathrm{a}}$ \\
\hline 20 & 8 & $9.9^{\mathrm{cd}}$ & $68.1^{\mathrm{a}}$ & $74.4^{\mathrm{b}}$ & $12.6^{\mathrm{b}}$ & $1.1^{\mathrm{b}}$ & $96.6^{\mathrm{ab}}$ & $2.2^{\mathrm{a}}$ & $97.7^{\mathrm{b}}$ & $4.5^{\mathrm{a}}$ & $54^{\mathrm{a}}$ \\
\hline 30 & 4 & $9.3^{\mathrm{ab}}$ & $71.3^{\mathrm{b}}$ & $76.5^{\mathrm{c}}$ & $10.4^{\mathrm{a}}$ & $0.8^{\mathrm{a}}$ & $96.1^{\mathrm{ab}}$ & $2.7^{\mathrm{ab}}$ & $95.6^{\mathrm{a}}$ & $6.1^{\mathrm{b}}$ & $53^{\mathrm{a}}$ \\
\hline 30 & 8 & $8.9^{\mathrm{a}}$ & $71.5^{\mathrm{b}}$ & $76.8^{\mathrm{c}}$ & $10.6^{\mathrm{a}}$ & $0.8^{\mathrm{a}}$ & $97.0^{\mathrm{b}}$ & $2.8^{\mathrm{ab}}$ & $96.9^{\mathrm{b}}$ & $6.2^{\mathrm{b}}$ & $55^{\mathrm{a}}$ \\
\hline SE & & 0.25 & 0.27 & 0.10 & 0.40 & 0.10 & 0.35 & 0.20 & 0.32 & 0.67 & 1.23 \\
\hline \multicolumn{12}{|c|}{ Analysis of variance and significance (p-values) } \\
\hline Moisture & & 0.022 & 0.000 & 0.000 & 0.008 & 0.028 & 0.765 & 0.065 & 0.047 & 0.006 & 0.632 \\
\hline Time & & 0.780 & 0.584 & 0.077 & 0.231 & 0.927 & 0.089 & 0.889 & 0.068 & 0.823 & 0.573 \\
\hline Moisture*Time & & 0.082 & 0.208 & 0.203 & 0.447 & 0.913 & 0.343 & 0.385 & 0.230 & 0.847 & 0.593 \\
\hline
\end{tabular}

$\Delta \mathrm{H}_{\text {gel }}, \Delta \mathrm{H}_{\text {amyl-lipid }}$ and $\Delta \mathrm{H}_{\text {ret }}$ : Enthalpy associated to starch gelatinization, dissociation of amylose-lipid complex and melting of the recrystallized amylopectin; $\mathrm{T}_{\mathrm{o}-\text { gel }}$ : onset temperature of gelatinization peak; $\mathrm{T}_{\mathrm{p} \text {-gel }}, \mathrm{T}_{\mathrm{p} \text {-ret, }}, \mathrm{T}_{\mathrm{p} \text {-amil }}$ : Peak Temperature of gelatinization, retrogradation and amylose-lipid complex dissociation peaks, respectively; $\mathrm{R}_{\mathrm{gel}}=2 \cdot\left(\mathrm{T}_{\mathrm{p}}-\mathrm{T}_{\mathrm{o}}\right)$ for the gelatinization peak; First: Scan carried out on native (un-gelatinized) sample. Second: Scan carried out on gelatinized samples after 7-days of storage. Mean values with different letters for the same parameter imply significant differences between means at $p<0.05$. SE: Pooled Standard Error obtained from ANOVA. In bold are highlighted the p-values $<0.05$ that mean the effects are significant with a confidence level $>95 \%$. 
onset and peak temperature of starch gelatinization increased to $3^{\circ} \mathrm{C}$ comparing to control when flours were moistened at $30 \%$. While the gelatinization temperature range, quantified by $\mathrm{R}_{\text {gel }}=$ $2 \cdot\left(\mathrm{T}_{\mathrm{p}}-\mathrm{T}_{\mathrm{o}}\right)$, decreased from $12^{\circ} \mathrm{C}$ to $10.5^{\circ} \mathrm{C}$ denoting more perfect amylopectin crystallites in MW-treated flours. Chiu and Solarek (2009) also reported that after hydrothermal treatments, the starch gelatinization temperature was higher and the gelatinization endotherm more defined. We also observed when crystallites perfection is higher, greater gelatinization temperatures are required to melt starch crystallites ( $\mathrm{Ji}$ et al. 2004). Therefore, the increase of gelatinization temperature observed in moistened treated flours would be in agreement with XRD results. The rise in gelatinization temperatures has also been associated with the formation of amyloseamylose and amylose-lipid complexes within the starch granule and an association and a more stable configuration in the granular structure (Lewandowicz et al. 2000). A slight but significant decrease in the gelatinization enthalpy of the microwaved-treated flours was observed probably because the samples underwent a partial gelatinization as a consequence of microwave treatment. The maximum reduction of $\Delta \mathrm{H}_{\mathrm{gel}}$ in the treated-flour samples with respect to the control flour was $14 \%$, very low when compared with the values of $72 \%$ and $47 \%$ found by Lewandowicz et al. (2000) for wheat and corn starch after a MWT. Those authors related the higher effect of MWT on partial gelatinization of wheat starch with its lower initial gelatinization temperature, $54^{\circ} \mathrm{C}$ versus $61^{\circ} \mathrm{C}$ for corn starch. The higher gelatinization temperature of rice flour (Table 1 ), $71^{\circ} \mathrm{C}$, could explain its lower $\Delta \mathrm{H}_{\text {gel }}$ reduction during $\mathrm{MW}$ treatment. Lewandowicz et al. (2000) also found that MW-treated waxy corn hardly changed its gelatinization enthalpy with respect to native corn starch; what means amylose content also plays an important role on this effect.

The second scan applied to gelatinized samples stored in the DSC pans at $(4 \pm 2)^{\circ} \mathrm{C}$ for 7 days (retrogradation scan) led also to two visible peaks. The first one, very wide, at a peak temperature of $\sim 54^{\circ} \mathrm{C}$ (Table 1), was related to the melting of the recrystallized amylopectin during the gel staling. The second peak was related to the amylose-lipid dissociation and appeared at the same temperature than in the first scan. As can be seen in Table 1, in the second scan the enthalpy of the amylose-lipid complex dissociation was similar for all the MW-treated samples and higher than in the first (gelatinization) scan. Eliasson (1994) reported that the increased values usually found during a second scan are probably due to better conditions for complex formation after the first heating because the leaking of amylose from granules can occurs at temperatures above the gelatinization temperature range. In the first scan, the samples treated with $30 \%$ water content led to a significantly smaller peak of amylose-lipid complex dissociation, with a reduction in enthalpy of $27 \%$ with respect to the control flour peak, which could be related to the higher difficulty in amylose leaching from the MW-treated granules. The amylopectin recrystallization extent was 35\% higher in samples treated by MW with 30\% initial water content than in native flour or in flours treated at $20 \%$ moisture content. This fact could represent a drawback in the shelf life of MW-treated flour gels.

\subsection{Effect of microwave treatment on pasting properties of rice flour}

The impact of time and initial water content of MWT process on the RVA primary parameters is evidenced by the significant changes in the pasting and gelling behavior of the treated flours (Table 2). 
Table 2. Effect of microwave treatment on the viscometric parameters of rice flours

\begin{tabular}{|c|c|c|c|c|c|c|c|c|}
\hline $\begin{array}{c}\text { Initial } \\
\text { Moisture } \\
\text { Content } \\
(\% \text { fb }) \\
\end{array}$ & $\begin{array}{c}\text { Microwave } \\
\text { treatment time } \\
\quad(\text { min })\end{array}$ & $\begin{array}{c}\text { Peak } \\
\text { Viscosity } \\
(\mathrm{mPa} \cdot \mathrm{s})\end{array}$ & $\begin{array}{c}\text { Trough } \\
\text { Viscosity } \\
(\mathrm{mPa} \cdot \mathrm{s})\end{array}$ & $\begin{array}{l}\text { Breakdown } \\
\text { Viscosity } \\
(\mathbf{m P a} \cdot \mathbf{s})\end{array}$ & $\begin{array}{c}\text { Final } \\
\text { Viscosity } \\
(\mathbf{m P a} \cdot \mathbf{s})\end{array}$ & $\begin{array}{l}\text { Setback } \\
\text { Viscosity } \\
(\mathbf{m P a} \cdot \mathbf{s})\end{array}$ & $\begin{array}{l}\text { Peak } \\
\text { time } \\
(\min )\end{array}$ & $\begin{array}{c}\text { Pasting } \\
\text { Temperature } \\
\left({ }^{\circ} \mathrm{C}\right)\end{array}$ \\
\hline Control & 0 & $2580^{\mathrm{g}}$ & $1565^{\mathrm{c}}$ & $1015^{\mathrm{g}}$ & $3729^{d}$ & $2163^{\mathrm{d}}$ & $5.60^{\mathrm{ab}}$ & $79.1^{\mathrm{a}}$ \\
\hline 20 & 2 & $2410^{\mathrm{f}}$ & $1579^{\mathrm{cd}}$ & $831^{\mathrm{f}}$ & $3651^{d}$ & $2072^{\mathrm{d}}$ & $5.55^{\mathrm{a}}$ & $83.6^{\mathrm{b}}$ \\
\hline 20 & 4 & $2342^{\mathrm{f}}$ & $1622^{\mathrm{cd}}$ & $720^{\mathrm{e}}$ & $3733^{\mathrm{d}}$ & $2111^{\mathrm{d}}$ & $5.47^{\mathrm{a}}$ & $83.2^{\mathrm{b}}$ \\
\hline 20 & 6 & $2096^{\mathrm{de}}$ & $1626^{\mathrm{d}}$ & $471^{\mathrm{c}}$ & $3723^{\mathrm{d}}$ & $2098^{d}$ & $5.49^{\mathrm{a}}$ & $84.5^{\mathrm{b}}$ \\
\hline 20 & 8 & $1612^{b}$ & $1423^{b}$ & $189^{\mathrm{a}}$ & $3214^{\mathrm{b}}$ & $1791^{\mathrm{bc}}$ & $5.58^{\mathrm{a}}$ & $86.9^{\mathrm{c}}$ \\
\hline 30 & 2 & $2120^{\mathrm{e}}$ & $1570^{c}$ & $550^{\mathrm{d}}$ & $3431^{\mathrm{c}}$ & $1862^{c}$ & $5.78^{\mathrm{c}}$ & $89.4^{\mathrm{d}}$ \\
\hline 30 & 4 & $2002^{d}$ & $1594^{\mathrm{cd}}$ & $408^{b}$ & $3351^{\mathrm{bc}}$ & $1757^{\mathrm{bc}}$ & $5.77^{\mathrm{c}}$ & $88.9^{d}$ \\
\hline 30 & 6 & $1760^{c}$ & $1561^{\mathrm{cd}}$ & $199^{\mathrm{a}}$ & $3245^{b}$ & $1684^{\mathrm{bc}}$ & $5.74^{\mathrm{bc}}$ & $86.9^{c}$ \\
\hline 30 & 8 & $1499^{\mathrm{a}}$ & $1357^{\mathrm{a}}$ & $142^{\mathrm{a}}$ & $2786^{\mathrm{a}}$ & $1429^{\mathrm{a}}$ & $6.02^{\mathrm{d}}$ & $89.8^{d}$ \\
\hline SE & & 48 & 26 & 29 & 70 & 52 & 0.05 & 0.57 \\
\hline \multicolumn{9}{|c|}{ Analysis of variance and significance (p-values) } \\
\hline \multicolumn{2}{|l|}{ Moisture } & 0.000 & 0.005 & 0.000 & 0.000 & 0.000 & 0.000 & 0.000 \\
\hline \multicolumn{2}{|l|}{ Time } & 0.000 & 0.000 & 0.000 & 0.000 & 0.000 & 0.000 & 0.000 \\
\hline \multicolumn{2}{|c|}{ Moisture*Time } & 0.035 & 0.378 & 0.000 & 0.103 & 0.085 & 0.061 & 0.000 \\
\hline
\end{tabular}

Mean values with different letters for the same parameter imply significant differences between means at p<0.05. SE: Pooled Standard Error obtained from ANOVA. In bold are highlighted the p-values $<0.05$ that mean the effects are significant with a confidence level $>95 \%$. 
Major effects on cooking and cooling parameters were noted for the longest treatment $(8 \mathrm{~min})$, resulting in increased paste temperature $\left(8^{\circ} \mathrm{C}\right.$ and $11^{\circ} \mathrm{C}$ for flours of $20 \%$ and $30 \%$ of initial moisture, respectively) and decreased peak (38\% and $42 \%)$, final (13\% and $25 \%$ ), breakdown (81\% and $86 \%$ ) and setback (17\% and $24 \%$ ) viscosities with respect to the control, native, flour. These changes can be explained by associations between chains in the amorphous region of the granule as well to changes in crystallinity during hydrothermal treatment (Watcharatewinkul et al., 2009) as was confirmed by X-ray diffraction assays. Greater effect was always observed in flours with higher initial water content, similar to that reported by other authors with respect to HMT treatments (Zavareze and Dias, 2011). However, the important change that took place in the two last minutes of treatment, from 6 to $8 \mathrm{~min}$, when the moisture of samples was $\leq 10 \%$ and the temperature $\sim 150^{\circ} \mathrm{C}$ makes us think that dry heat treatment had also a high impact on flour properties.

The MWT-induced reduction in the breakdown and setback of the flours (Table 2) shows that treated samples were more stable during heating and stirring and had a lower amylose retrogradation. The reduction in amylose leaching from starch granules as consequence of the promotion of amylose-amylose and/or amylose-amylopectin chain interactions could explain these results (Chung et al., 2009).

\section{Conclusions}

The MW absorption capacity of rice flour exhibited a positive quadratic relationship with the water content while the flour dry matter did not show any radiation absorption capacity. However, the decrease in the specific heat of the flour associated with the loss of water was responsible for the significant change in the temperature of the samples, which reached $150^{\circ} \mathrm{C}$ in $4 \mathrm{~min}$, although the water content of the flour decreased drastically during the treatment. The dry-heat treatment of the flour that took place in the last 4 min of the MWT could explain the increase in crystallinity observed in the treated samples. Microwave assisted thermal treatment of rice flour changed its thermal and pasting properties as morphological structure of flour particles and crystallinity/amorphous ratio. The changes observed in thermal properties of treated flour revealed the crucial impact of initial moisture content on the significant rising of gelatinization temperature, the decrease in the gelatinization enthalpy and the enhancement of the amylopectin recrystallization after seven days of storage. All those changes resulted in functional properties alteration represented by distinct pasting behavior of microwave irradiated rice flours. They showed higher pasting temperatures, lower peak, breakdown and setback viscosities than the native flour particularly when flour samples were treated at the highest (30\%) initial moisture content. The results proved the efficiency of microwave assisted thermal treatment on physical changes of rice flour that took place in significantly shorter periods than conventional HMT. Further studies are needed to clarify the relative importance of hydrothermal and dry-thermal stages in the MWT process. Also pending is the study of the ability of the MW-treated flours to improve the quality of gluten-free food products.

\section{Acknowledgments}

This project has received funding from the European Union's Horizon 2020 research and innovation programme Marie Sklodowska-Curie grant agreement No 706102 BREADforALL. The authors thank the financial support of the Ministerio de Economía y Competitividad and the European Regional Development Fund (AGL2015-63849-C2-2-R) and the Consejería de Educación (Junta de Castilla y León)/FEDER (Project VA072P17). The authors thank to 
Beatriz de Lamo for measuring the temperature evolution of the flour versus the microwave treatment time. Marina Villanueva thanks the Junta de Castilla y León for her doctorate grant.

\section{References}

American Association of Cereal Chemists (AACC), 2000. Approved Methods of the AACC. Method 44-19, $10^{\text {th }}$ ed. The Association, St. Paul, MN.

Abebe, W., \& Ronda, F. (2015). Flowability, moisture sorption and thermal properties of tef [Eragrostis tef (Zucc.) Trotter] grain flours. Journal of Cereal Science, 63, 14-20.

Amadou, I., Gounga, M. E., Shi, Y.-H., \& Le, G.-W. (2014). Fermentation and heat-moisture treatment induced changes on the physicochemical properties of foxtail millet (Setaria italica) flour. Food and Bioproducts Processing, 92(1), 38-45.

Anderson, A. K., \& Guraya, H. S. (2006). Effects of microwave heat-moisture treatment on properties of waxy and non-waxy rice starches. Food Chemistry, 97(2), 318-323.

Ashraf, S., Saeed, S. M. G., Sayeed, S. A., \& Ali, R. (2012). Impact of microwave treatment on the functionality of cereals and legumes. International Journal of Agriculture and Biology, 14(3), 365-370.

BeMiller, J. N., \& Huber, K. C. (2015). Physical modification of food starch functionalities. Annual Review of Food Science and Technology, 6, 19-69.

Bourekoua, H., Benatallah, L., Zidoune, M. N., \& Rosell, C. M. (2016). Developing gluten free bakery improvers by hydrothermal treatment of rice and corn flours. LWT - Food Science and Technology, 73, 342-350.

Cappa, C., Barbosa-Cánovas, G. V, Lucisano, M., \& Mariotti, M. (2016). Effect of high pressure processing on the baking aptitude of corn starch and rice flour. $L W T$ - Food Science and Technology, 73, 20-27.

Carrera, Y., Utrilla-Coello, R., Bello-Pérez, A., Alvarez-Ramirez, J., Vernon-Carter, E.J., 2015. In vitro digestibility, crystallinity, rheological, thermal, particle size and morphological characteristics of pinole, a traditional energy food obtained from toasted ground maize. Carbohydr. Polym. 123, 246-255.

Chiu, C.-W., \& Solarek, D. (2009). Modification of Starches. In BeMiller, J. and Whistler, R. (eds.) Starch Chemistry and Technology, $3^{\text {rd }}$ edn. Academic Press, New York, 629$655)$.

Chung, H.-J., Liu, Q., \& Hoover, R. (2009). Impact of annealing and heat-moisture treatment on rapidly digestible, slowly digestible and resistant starch levels in native and gelatinized corn, pea and lentil starches. Carbohydrate Polymers, 75(3), 436-447.

Eliasson, A.-C. (1994). Interactions between starch and lipids studied by DSC. Thermochimica Acta, 246(2), 343-356.

Guo, W., Wang, S., Tiwari, G., Johnson, J. A., \& Tang, J. (2010). Temperature and moisture dependent dielectric properties of legume flour associated with dielectric heating. LWT - Food Science and Technology, 43(2), 193-201.

Ince, A. D., \& Turner, A. (1965). The determination of moisture in plain cakes by a microwave attenuation technique. The Analyst, 90(1076), 692-696.

Ji, Y., Ao, Z., Han, J.A., J.L., BeMiller, J.N., 2004. Waxy maize starch subpopulations with different gelatinization temperatures. Carbohydrate Polymers. 57, 177-190.

Kim, H. R., Kim, K. M., Lee, J.-H., Yoo, S.-H., Lee, S. M., \& Kim, K.-O. (2016). Physicochemical properties of enzyme-treated waxy rice flour and expansion 
properties of Gangjung (a traditional Korean oil-puffed rice snack). Food Science and Biotechnology, 25(5), 1353-1360

Lewandowicz, G., Fornal, J., \& Walkowski, A. (1997). Effect of microwave radiation on physico-chemical properties and structure of potato and tapioca starches. Carbohydrate Polymers, 34(4), 213-220.

Lewandowicz, G., Jankowski, T., \& Fornal, J. (2000). Effect of microwave radiation on physico-chemical properties and structure of cereal starches. Carbohydrate Polymers, 42(2), 193-199.

Majzoobi, M., Pesaran, Y., Mesbahi, G., \& Farahnaky, A. (2016). Evaluation of the Effects of Hydrothermal Treatment on Rice Flour and Its Related Starch. International Journal of Food Properties, 19(9), 2135-2145.

Nawaz MA, Gaiani C, Fukai S, Bhandari B. X-ray photoelectron spectroscopic analysis of rice kernels and flours: Measurement of surface chemical composition. Food Chem 2016; 212:349-357.

Okabe, T., Huang, M. T., \& Okamura, S. (1973). A new method for the measurement of grain moisture content by the use of microwaves. Journal of Agricultural Engineering Research, 18(1), 59-66.

Pérez-Quirce, S., Ronda, F., Melendre, C., Lazaridou, A., \& Biliaderis, C. G. (2016). Inactivation of Endogenous Rice Flour $\beta$-Glucanase by Microwave Radiation and Impact on Physico-chemical Properties of the Treated Flour. Food and Bioprocess Technology, 9(9), 1562-1573.

Pérez-Quirce, S., Lazaridou, A., Biliaderis, C. G., \& Ronda, F. (2017). Effect of $\beta$-glucan molecular weight on rice flour dough rheology, quality parameters of breads and in vitro starch digestibility. LWT - Food Science and Technology, 82, 446-453.

Phongthai, S., D'Amico, S., Schoenlechner, R., Homthawornchoo, W., \& Rawdkuen, S. (2017). Effects of protein enrichment on the properties of rice flour based gluten-free pasta. LWT - Food Science and Technology, 80, 378-385.

Qiu, C., Cao, J., Xiong, L., \& Sun, Q. (2015). Differences in physicochemical, morphological, and structural properties between rice starch and rice flour modified by dry heat treatment. Starch/Staerke, 67(9-10), 756-764.

Ronda, F., Perez-Quirce, S., Lazaridou, A., \& Biliaderis, C. G. (2015). Effect of barley and oat $\beta$-glucan concentrates on gluten-free rice-based doughs and bread characteristics. Food Hydrocolloids, 48, 197-207.

Silva, W. M. F., Biduski, B., Lima, K. O., Pinto, V. Z., Hoffmann, J. F., Vanier, N. L., \& Dias, A. R. G. (2017). Starch digestibility and molecular weight distribution of proteins in rice grains subjected to heat-moisture treatment. Food Chemistry, 219, 260-267.

Siruguri V, Ganguly C, Bhat RV. Utilization of mouldy sorghum and Cassia tora through fermentation for feed purposes. Afr J Biotechnol 2009;8(22):6349-6354.

Takahashi, T., Miura, M., Ohisa, N., Mori, K., \& Kobayashi, S. (2005). Heat treatments of milled rice and properties of the flours. Cereal Chemistry, 82(2), 228-232.

Villanueva, M., Mauro, R. R., Collar, C., \& Ronda, F. (2015). Acidification of protein-enriched rice starch doughs: effects on breadmaking. European Food Research and Technology, 240(4), 783-794.

Watcharatewinkul, Y., Puttanlek, C., Rungsardthong, V., \& Uttapap, D. (2009). Pasting properties of a heat-moisture treated canna starch in relation to its structural characteristics. Carbohydrate Polymers, 75(3), 505-511. 
Yano, H., Fukui, A., Kajiwara, K., Kobayashi, I., Yoza, K.-I., Satake, A., \& Villeneuve, M. (2017). Development of gluten-free rice bread: Pickering stabilization as a possible batter-swelling mechanism. LWT - Food Science and Technology, 79, 632-639.

Zavareze, E. D. R., \& Dias, A. R. G. (2011). Impact of heat-moisture treatment and annealing in starches: A review. Carbohydrate Polymers, 83(2), 317-328. 